\title{
MS33-P16 | Giant Supramolecules as Molecular Containers
}

Virovets, Alexander (University of Regensburg, Regensburg, GER); Peresypkina, Dr. Eugenia (University of Regensburg, Regensburg, GER); Scheer, Prof. Dr. Manfred (University of Regensburg, Regensburg, GER)

One of the most outstanding areas in the modern coordination chemistry is the rational design of giant supramolecules built up from metal ions connected to each other via polytopic ligands resulting in large hollow cages. The systematic approach to the synthesis of hollow supramolecules developed in our group is the coordination of $\mathrm{Cu}^{+}$and $\mathrm{Ag}^{+}$cations to phosphorus atoms of the pentaphosphaferrocenes, $\left[C p^{\mathrm{R}} \mathrm{Fe}\left(\eta^{5}-\mathrm{P}_{5}\right)\right]\left(\mathrm{Cp}{ }^{\mathrm{R}}=\eta^{5}-\right.$ $\mathrm{C}_{5} \mathrm{R}_{5}, \mathrm{R}=\mathrm{Me}(\mathrm{Cp} *), \mathrm{CH}_{2} \mathrm{Ph}\left(\mathrm{Cp}^{\mathrm{Bn}}\right)$, etc.) [1-3]. The central cavity of these pentaphosphaferrocene-based supramolecules (reaching 0.60-1.35 nm) can include various guest molecules like metastable $\mathrm{P}_{4}$ and $\mathrm{As}_{4}$, various neutral and anionic metallocenes and triple-decker complexes, or cage molecules. The hosting supramolecules can often be adjusted to the size, shape and charge of the guest molecules. Moreover, the usage of $\mathrm{AgSbF}$, $\left[\mathrm{Cp}^{*} \mathrm{Fe}\left(\eta^{5}\right.\right.$ $\left.P_{5}\right)$ ] and $N \equiv C\left(C_{2}\right)_{n} C \equiv N(n=5-12)$ linkers allowed us to obtain coordination polymers with giant supramolecular nodes encapsulating $\left[\mathrm{Cp} * \mathrm{Fe}\left(\eta^{5}-\mathrm{P}_{5}\right)\right]$ and $\mathrm{P}_{4}$ molecules or $\mathrm{SbF}_{6}{ }^{-}$anion.

Financial support from the ERC grant ADG 339072 is gratefully acknowledged. The research was partly done at the light source PETRA III at DESY.

[1] E. Peresypkina, et al (2016) Structure and Bonding 174, 321.

[2] H. Brake, et al (2019) Chem. Sci. 10, 2940.

[3] E. Peresypkina, et al (2018) Chem.-A Eur. J., 24, 2503. 